\title{
LAS DECISIONES DEL GASTO PÚBLICO Y EL ROL DE LOS MUNICIPIOS EN EL DESARROLLO LOCAL EN ARGENTINA. UN ABORDAJE DESDE LA AUTONOMÍA MUNICIPAL Y LOS ACTORES SOCIALES Y POLITICOS (2004-2006)*
}

\author{
Mg. Héctor Flores \\ Licenciado en Administración, Magíster en Economía y Negocios, decano de la Facultad \\ de Ciencias Económicas, Jurídicas y Sociales (FSCJyS), Universidad Nacional de San Luis \\ (UNSL). Investigador y docente en FCEJS-UNSL. \\ hd.hector@gmail.com. \\ Mg. Martín Gil \\ Contador Público Nacional, Magíster en Economía y Negocios, Investigador y docente \\ en FCEJS-UNSL. \\ m.gil1979@hotmail.com.ar \\ Mg. Estela Iparraguirre \\ Contador Público Nacional. Investigador y docente en FCEJS-UNSL. \\ eiparra@gmail.com

\section{Dr. Cristian Altavilla} \\ Abogado, Doctor en Derecho y Ciencias Sociales por la Universidad Nacional de \\ Córdoba (UNC) Argentina. Investigador y docente en la Facultad de Derecho, UNC y en \\ la FCEJS-UNSL. Becario postdoctoral CONICET. \\ cristianaltavilla@hotmail.com
}

\section{RESUMEN:}

El desarrollo endógeno es un tema prioritario en la agenda municipal, atento el rol de liderazgo que les compete a los gobiernos locales en este proceso. A raíz de distintos procesos de descentralización operados desde el nivel central de gobierno hacia los subnacionales, los municipios se han visto obligados a diseñar estrategias y políticas públicas conjuntas con los distintos actores locales, individuos, organizaciones, políticos y asociaciones de la sociedad civil en general, en la búsqueda de soluciones a las problemáticas que plantea la sociedad hoy.

En este trabajo se intentará analizar cómo se inserta el gobierno local, en tanto articulador de los esfuerzos de la comunidad, dentro de la estructura federal en la República Argentina, el rol asignado y los recursos de que dispone para una eficaz gestión de sus prioridades, focalizando el análisis en las preferencias de los

\footnotetext{
" Una versión preliminar de este trabajo fue presentada como ponencia en el XII Congreso Iberoamericano de Municipalistas "Una agenda territorial para los objetivos de desarrollo sostenible", ciudad de Manizales, Caldas, Colombia, 24 y 28 de septiembre de 2017.

Los autores son integrantes del Proyecto de Investigación PROICO 15-0716 "Estructura y Marco Institucional del Desarrollo en la Provincia de San Luis. Un Enfoque Sistémico”, Universidad Nacional de San Luis (UNSL) - Secretaría de Ciencia y Técnica. Facultad de Ciencias Económicas, Jurídicas y Sociales (FSCJS). Avda. 25 de Mayo 384 -5730 - Villa Mercedes, provincia de San Luis. Tel-Fax (02657) 434545 .
} 
intendentes sobre el gasto público y sobre la capacidad financiera de estos entes locales. A partir de este análisis, se extraen algunas conclusiones preliminares acerca de las posibilidades reales de los gobiernos locales en Argentina para fijar sus agendas y de su efectiva capacidad para transformarse en motores del desarrollo local; seguido de una breve discusión con la literatura local y regional que gira en torno al concepto de autonomía y sobre su estado actual, para finalmente propiciar nuevas líneas de investigación sobre esta temática de relevancia.

PALABRAS CLAVE: Desarrollo local, descentralización, autonomía municipal, gasto público local, políticas públicas

\section{PUBLIC SPENDING DECISIONS AND THE ROLE OF MUNICIPALITIES IN LOCAL DEVELOPMENT IN ARGENTINA. AN APPROACH FROM THE MUNICIPAL AUTONOMY AND SOCIAL AND POLITICAL ACTORS (2004-2006)}

\section{ABSTRACT:}

The endogenous development is a priority topic in the local agenda, given the leadership role that compete them in this process.

In the aftermath of different decentralization processes, municipalities were forced to design strategies and joint public policies with different local actors - namely individuals, organizations, politicians, and civil society associations - in the seek for solutions to the current challenges associated with the present-day society.

This paper will attempt to analyze the way local governments insert within the federal structure in Argentina, the role assigned to them and the available resources for an effective management of their priorities, focusing the analysis on mayors' preferences about local public spending and the actual financial capacity of these local entities. On the basis of this analysis, the paper ends with some preliminary conclusions regarding the actual possibilities of local governments in Argentina to set their own agendas and of their effective ability to transform themselves in the motor and driving force of local development; followed by a brief discussion with local and regional literature revolving around the concept of autonomy and its current state to finally bring about new research lines in this topicality issue.

KEY WORDS: Local development, decentralization, municipal autonomy, local public spending, public policies

\section{INTRODUCClóN}

La revalorización del rol municipal como principal actor del desarrollo local fue producto de la reforma del Estado operada en la Argentina durante la década del '90. En este proceso de transformación, el gobierno local se vio obligado a sumar a su tradicional papel de prestador de servicios básicos (eminentemente urbanísticos), nuevas funciones tendientes a satisfacer las demandas crecientes y cada vez más complejas de la sociedad actual.

Los gobiernos locales pasaron de ser meros prestadores de servicios básicos, a estar a cargo de nuevas funciones y competencias en materia relacionada al bienestar social. 
Así, mientras en la década del '80 poco más de un tercio de las constituciones provinciales reconocieron expresamente la plena autonomía de los gobiernos municipales (proceso al que se le sumarían el resto de las provincias a lo largo de las dos décadas posteriores), en la década del '90 comienzan a hacerse cargo de modo efectivo de una serie de importantes funciones, tales como salud y educación, mediante procesos de descentralización operados desde los gobiernos provinciales; un cúmulo importante de nuevas funciones comenzaron a integrar la agenda municipal. En particular, pueden destacarse tres áreas genéricas donde los municipios comenzaron a tener mayor injerencia: políticas sociales (cuestiones referidas al bienestar general de la población); promoción económica (referidas principalmente a la fomento e incentivación de la inversión y el empleo) y cuestiones medioambientales (Tecco 1997). Como se verá más adelante, las políticas sociales han sido, dentro de este grupo, las más importantes y las que mayores gastos implicaron en la nueva gestión municipal. Dentro de este grupo cabe mencionar los distintos planes y programas nacionales gestionados directamente por los municipios, en particular desde el año 2003 cuando se produce un cambio importante en el contexto político y económico nacional e internacional con un fuerte impacto en los niveles de recaudación, que se traduce en mayores recursos tributarios, en especial de impuestos federales.

A este nuevo cúmulo de competencias (ahora de gestión municipal), cabe sumar dos elementos que contribuyeron a la ampliación de los roles de los gobiernos locales: por un lado, la ausencia de políticas nacionales y provinciales explícitas de desarrollo regional y por otro, la búsqueda, por parte de los propios municipios, de economías de escala para la prestación de servicios públicos (Tecco 1997).

A pesar de los reconocimientos constitucionales de la autonomía municipal y la efectiva transferencia de servicios y funciones, un problema puntual quedó irresoluto: la cuestión del financiamiento. Esta cuestión reconoce a su vez como antecedente la descentralización previa de servicios y funciones desde el gobierno federal hacia los provinciales que no fueron tampoco acompañados de los respectivos recursos financieros para afrontar tales gastos (Cetrángolo y Jiménez 2002, Altavilla 2016a). De esta manera, así como desde el nivel nacional se descentralizó el gasto al tiempo que se recentralizaron los recursos, las provincias replicaron este mecanismo con sus municipios. La consecuencia de estos procesos, apresurados, mal orientados y defectuosamente diseñados, las provincias primero y los municipios después, quedaron a cargo de un importante cúmulo de competencias sin contar con recursos genuinos suficientes para afrontar semejantes gastos; en este contexto, la dependencia financiera de las provincias y particularmente de los municipios (respecto de recursos tanto provinciales como nacionales) pasó a ser la principal característica de las relaciones intergubernamentales en Argentina de las últimas tres décadas.

Este panorama resulta poco alentador para la autonomía municipal - tan declamada en los textos constitucionales - afectando uno de sus aspectos más sensibles y cruciales, como lo es el económico-financiero. La ausencia o deficiencia de este aspecto trae importantes consecuencias para el desarrollo local, ya que termina por afectar la gestión municipal, condicionando por ejemplo, la decisión del gasto. No se trata simplemente de dotar de mayor independencia a los gobiernos municipales en la gestión de los asuntos locales, sino de proveerlos de recursos suficientes para la 
satisfacción de las demandas sociales y la posibilidad de una planificación estratégica para el desarrollo local.

El objetivo de este trabajo es analizar la complejidad de las decisiones gubernamentales en la instancia local y el grado de autonomía de los intendentes al momento de seleccionar estrategias de acción, teniendo en cuenta la influencia de los distintos actores en estos procesos. La hipótesis de este trabajo es que la autonomía municipal reconocida constitucionalmente se ve seriamente comprometida por la ausencia efectiva de recursos propios y genuinos de los entes locales, poniendo en riesgo su capacidad real para la decisión, gestión e implementación de políticas públicas locales y, en particular, para definirlas de acuerdo a las preferencias locales. Por el contrario, puede observarse que tales decisiones vienen dadas desde los niveles superiores de gobierno, basadas, en consecuencia, en las preferencias de estos niveles.

\section{Municipios argentinos, autonomía y finanzas}

Actualmente existen 2.294 gobiernos locales en argentina, de acuerdo al Censo Nacional realizado por Instituto Nacional de Estadísticas y Censos (INDEC) en el año 2010, de los cuales solo la mitad están constituidos como municipios. Independientemente de la denominación que reciban estos gobiernos locales en el derecho provincial (municipios, comunas, etc.), lo cierto es que más del $90 \%$ de la población del país vive baja la jurisdicción de un gobierno local. Por otra parte también es destacable que desde el punto de vista del tan discutido concepto de presión fiscal esta institución apenas representa para el año 2013 el 1,4\% como porcentaje del PBI (ver TABLA 15).

La temática del desarrollo endógeno y la importancia del rol de los municipios como orientador de los procesos para su logro, requiere el diseño de los mecanismos a través de los cuales se genera e influencia el proceso decisorio vinculado al gasto público, y la implementación de las políticas públicas conducentes a alcanzar los objetivos de dicho gasto. La transformación de las agendas locales en pos del logro de procesos de desarrollo ha significado la asunción de los nuevos roles municipales lo que se relaciona con el énfasis del concepto de autonomía local. Según opina Cáceres (2008), en la temática municipalista se ha enfatizado más la dimensión formal y administrativa del concepto de autonomía, pero en muchas oportunidades, estos análisis han dejado de lado los factores sociales y políticos que hacen a su real vigencia.

Cuando el diseño institucional permite la autonomía plena (es decir en los órdenes institucional, administrativo, político y financiero) es de suponer que los intendentes deberían poseer las herramientas indispensables para gestionar el uso de los recursos públicos en un escenario en el que se han incrementado las competencias delegadas a los municipios. En el ámbito formal-legal, esto se traduce como independencia en la toma de decisiones con respecto a los otros niveles de gobierno y los distintos participantes en la vida económica, política y social del municipio (en forma coincidente, Pratchett 2004). De hecho los intendentes tendrán múltiples cuestiones en cuenta en la toma de decisiones a la hora de gestionar los fondos comunales. 
La ampliación de funciones de los municipios no ha sido sólo en número sino también en complejidad. Ya desde mediados de la década del 50 , la teoría clásica del federalismo fiscal (Tiebout 1956, Oates 1972) planteaba la necesidad (o conveniencia) de que los servicios públicos básicos fueran prestados por el nivel de gobierno más próximo a la ciudadanía, ya que éstos "reflejan las preferencias de la población de manera más adecuada de lo que pudiera hacerlo el nivel nacional" (Tiebout 1956:416). Pero, según opinión de Macon (2001), hace varias décadas que se viene tratando el tema de la descentralización en forma independiente de la organización institucional de los gobiernos, unitarios o federales. Es un proceso que se ha cumplido en numerosos países y su tratamiento se ha fundamentado en el principio de subsidiariedad, según el cual los niveles de gobierno nacional y/o intermedios deben actuar en forma supletoria. Esto significa que las decisiones sean adoptadas en el nivel más próximo al ciudadano, debiendo las unidades políticas o administrativas locales prestar los servicios con niveles de eficiencia, transparencia y eficacia adecuados. Si esto no es posible, debe intervenir el nivel superior de gobierno, subsidiariamente. (Macon, 2001).

El crecimiento de estos requerimientos de la ciudadanía ha complejizado las decisiones de los intendentes en cuanto al tipo y quantum del gasto municipal, ya que la tendencia es a esperar de ellos las soluciones a la diversidad de problemas que se presentan en los municipios. Por lo que el ejercicio de la autonomía se vincula estrechamente a la capacidad financiera de los municipios para la satisfacción de las demandas ciudadanas. El concepto de autonomía local (así como el de democracia local), en consecuencia, no es una cuestión meramente teórica, sino también a los fines políticos ya que "conduce a objetivos y resultados políticos confusos" (Pratchett 2004:359). Carecer de ella y de la posibilidad de una gestión autónoma del gasto público con respecto de otros niveles gubernamentales, transforma al gobierno local en una mera delegación administrativa.

\section{Los recursos municipales}

El ejercicio de la autonomía financiera encuentra uno de sus pilares en el carácter originario del poder tributario municipal: la Constitución Nacional establece en su art. $5^{\circ}$ (que proviene del texto originario de 1853/60) que las provincias dicten su propia constitución, asegurando el régimen municipal, dejando librado a cada una de ellas establecer el grado de autonomía que los gobiernos locales tendrán. La mención escueta y sintética del art. $5^{\circ}$ de la Constitución histórica abrió paso a un gran debate en la legislación, la doctrina y la jurisprudencia por más de un siglo y medio entre aquellos que sostenían que los municipios podían ser entes autárquicos (es decir, meras descentralizaciones administrativas del poder provincial) y aquellos que sostuvieron que el art. $5^{\circ}$ obligaba a las provincias a asegurar la autonomía de sus municipios ${ }^{1}$. Esta discusión se zanjaría recién con la reforma a la Constitución Nacional de 1994, donde se agregaría un nuevo artículo, actual 123, el que expresamente dispone que "Cada provincia dicta su propia constitución, conforme a lo dispuesto por el Artículo $5^{\circ}$ asegurando la autonomía municipal y reglando su alcance y contenido en

\footnotetext{
1 Los pormenores de esta discusión exceden el marco de este trabajo. Para un análisis más profundo sobre ambas posturas, pueden consultarse Hernández 2003, Abalos 2003, Rosatti 2012, entre otros.
} 
el orden institucional, político, administrativo, económico y financiero". A raíz de esta disposición, queda establecido, a modo de imperativo, que las constituciones provinciales deberán reconocer la autonomía de sus municipios en los cinco aspectos mencionados, debiendo destacarse, a los efectos de este trabajo, el aspecto económico-financiero. Este artículo reconoce como antecedente inmediato a las propias constituciones provinciales que ya en la década del 50 y luego en la del 80 reconocieron expresamente la autonomía de sus municipios ${ }^{2}$. En las dos décadas posteriores, el resto de las provincias irían adecuando sus regímenes municipales a las nuevas disposiciones de la Constitución Nacional ${ }^{3}$.

Tanto los textos constitucionales provinciales como la propia Constitución Nacional, reconocen expresamente la autonomía de los municipios $y$, específicamente, su autonomía económico-financiera. Este aspecto de la autonomía se traduce, entre otras cosas pero fundamentalmente, en la potestad impositiva de los entes locales - es decir, en la posibilidad de generar sus propios recursos de manera genuina, sean estos impuestos, tasas o contribuciones especiales.

Por lo tanto los municipios tienen facultades para dictar sus propias normas impositivas, a efectos de que la recaudación permita financiar el cumplimiento de las funciones tradicionales tales como la administración del presupuesto y prestación de servicios básicos. A esto se agrega la necesidad de satisfacer las demandas crecientes de la comunidad lo que obliga a los gobiernos locales a desarrollar estrategias financieras para su concreción. Desde el punto de vista constitucional, los municipios tienen también reconocido una amplia gama de competencias y funciones en materia de bienestar social, tales como salud, vivienda, educación (primaria, secundaria e incluso universitaria), asistencia social, etc. Gran parte de las constituciones provinciales reconocen la universalidad de la competencia municipal, es decir, que los municipios se encuentran habilitados a "ejercer cualquier otra función o atribución de interés municipal" como reza la constitución de la provincia de Córdoba (art. 186, inc. 14). Es así que del diseño constitucional provincial emerge la figura del municipio como un Estado de bienestar, es decir, un estado municipal de bienestar. De este cúmulo de competencias reconocidas explícita e implícitamente por las constituciones (a través de cláusulas generales como la transcripta anteriormente) también puede concluirse válidamente la potestad tributaria de los municipios, como un reconocimiento al "derecho a los medios" (Rosatti 2012a y 2012b). Esto quiere decir que si los entes locales tienen atribuciones y competencias sobre determinadas materias, también tienen la posibilidad de recaudar los fondos necesarios para costearlos - so pena de

\footnotetext{
${ }^{2}$ En la década del 50, nueve provincias reconocerán en sus constituciones la autonomía municipal: Chubut; Río Negro; Formosa; Neuquén, Santa Cruz y Chaco en 1957, Misiones en 1958 y Santiago del Estero en 1960. Todas - salvo la última - fueron Territorios Nacionales, y al ser reconocidas como provincias dictaron sus primeras constituciones. Hacia la década del ochenta, otro grupo de 7 provincias reforman sus constituciones y prevén expresamente la autonomía municipal: San Juan, La Rioja, Salta y Jujuy en 1986; Córdoba y San Luis en 1987; Catamarca en 1988. En 1991 se provincializa el último de los territorios nacionales, Tierra del Fuego y sanciona su primera constitución en 1991 reconociendo también la autonomía municipal; Corrientes lo hará en 1993. Cuando se produce la reforma de la Constitución Nacional en 1994, diecisiete provincias habían ya reconocido la autonomía municipal.

3 Con posterioridad, lo harían las provincias de Tucumán y Entre Ríos en 2008. Tras estas modificaciones, actualmente 20 provincias reconocen expresamente la autonomía municipal. Solo tres provincias no la reconocen: Buenos Aires, Santa Fe y Mendoza. Las dos últimas no modificaron sus constituciones en ninguno de los ciclos constituyentes mencionados anteriormente y mantienen vigentes sus constituciones de 1962 y 1916, respectivamente (Altavilla 2015).
} 
quedar relegados a meras descentralizaciones administrativas de los gobiernos provinciales. Si los gobiernos municipales no contasen con recursos propios para definir sus agendas y determinar el gasto público, sino que por el contrario, dependiesen exclusivamente o en gran medida de los recursos provenientes de otras jurisdicciones (provincial o federal - ver TABLA 13), la amplia autonomía constitucionalmente reconocida quedaría reducida a una mera ficción, desde que quien invierte es quien decide el destino del gasto. De esta manera, la ausencia de autonomía financiera repercute sobre la efectiva vigencia de la autonomía en sus demás aspectos; así, la autonomía institucional, política y administrativa se vería afectada tanto por la falta de recursos como por la imprevisibilidad en cuanto a los montos a percibir, "como así también en lo relativo a su disponibilidad cierta y oportuna, restando toda certeza a su gestión"4.

A pesar del amplio reconocimiento de competencias y servicios en manos de los municipios y del expreso reconocimiento de potestades tributarias, es posible afirmar que existe una gran brecha entre este aspecto formal con la realidad concreta de la autonomía municipal. Si bien es posible sostener que los tres niveles de gobierno reconocidos en la federación argentina - nacional, provincial y municipal - cuentan con potestad tributaria originaria (ver al respecto Giuliani Fonrouge 2003), la distribución de la competencia tributaria muestra una realidad distinta. La distribución acerca de qué impuestos (o tipos de impuestos) puede cada nivel de gobierno establecer en particular ha sido una cuestión problemática en Argentina desde su formación misma como Estado-Nación. Ya el texto de la Constitución de 1853/1860 establecía una delimitación un tanto vaga entre provincias y nación, sin mencionar a los municipios en este reparto. En la reforma de 1994 se aclararía lo que en la práctica - al menos desde 1935 - había sido algo ya resuelto entre nación y provincias a través de específicos mecanismos de participación del producido de impuestos nacionales con las provincias, sistema que en nuestro país pasó a conocerse como régimen de coparticipación federal de impuestos ${ }^{5}$.

Así, por ejemplo, el texto constitucional de 1853/1860 establecía en el art. $4^{\circ}$ que el tesoro nacional se compone del "producto de derechos de importación y exportación" y "de las demás contribuciones que equitativa y proporcionalmente a la población imponga el Congreso General" (por mencionar solo los de origen tributario); el art. 67, sobre las atribuciones del Congreso de la Nación, establecía en su inciso $2^{\circ}$ "Imponer contribuciones directas por tiempo determinado y proporcionalmente iguales en todo el territorio de la Nación, siempre que la defensa, seguridad común y bien general del Estado lo exijan" y a su vez el art. 108 prohibía a las provincias establecer derechos de importación y exportación, quedando en consecuencia como una facultad exclusiva del gobierno federal. De acuerdo al esquema de la Constitución de 1853/1860, era facultad privativa y exclusiva del gobierno federal establecer derechos de importación

\footnotetext{
${ }^{4}$ Como arguyó el Municipio de La Rioja en la causa "Recurso de hecho deducido por la Municipalidad de La Rioja en la causa Intendente Municipal Capital s/ amparo", fallado por la CSJN el 14 de noviembre de 2014 (ver Dictamen de la Procuración General de la Nación, en la misma causa).

5 Este mecanismo consiste básicamente en concentrar la legislación y recaudación de impuestos concurrentes entre ambos niveles de gobierno en el nivel central, el que luego de recaudar dichos impuestos, distribuye su producido con las provincias, de acuerdo a fórmulas preestablecidas. Como contrapartida, y con la finalidad de evitar los efectos perniciosos de la doble imposición, las provincias se comprometen a no recaudar los tributos comprendidos dentro del régimen.
} 
y exportación y facultad excepcional el de establecer impuestos directos; respecto de las provincias nada decía, pero por aplicación del entonces art. 104 (actual 121 - sin modificaciones) que establece el principios general sobre distribución de competencias entre nación y provincias, confiere a favor de estas últimas la cláusula residual, disponiendo que "Las provincias conservan todo el poder no delegado por esta Constitución al Gobierno federal". De esta manera se interpretó que como lo único que estaba prohibido por la Constitución era establecer derechos aduaneros, las provincias conservaban en consecuencia la potestad de establecer impuestos directos e indirectos como competencia propia y como, en principio, nada se establecía respecto de la facultad del gobierno federal de establecer impuestos indirectos, se entendía, por aplicación del mismo principio, que se encontraba vedada a éste.

Pero debido a las exigencias económicas, y en particular para sortear los efectos de las crisis económicas, el gobierno federal empezó a establecer primero impuestos indirectos (crisis económica mundial de 1890) y luego directos (crisis económica mundial de 1930) que, aunque por tiempo determinado como manda la Constitución, los prorrogó indefinidamente hasta la actualidad (uno de ellos es, precisamente, el Impuesto a las Ganancias).

En 1994 toda la primera parte de la constitución de 1853/1860 no fue modificada, ya que solo se habilitó la reforma de la segunda parte. Asimismo, las reformas producidas fueron más bien agregados al texto histórico que reformas a su articulado. Entre estos agregados estuvo el art. 75 , inc. $2^{\circ}$ (anterior art. 67 , inc. $2^{\circ}$ ) donde se aclara que la potestad de establecer impuestos indirectos es una competencia concurrente entre nación y provincias. Además, establece que el producido de estos impuestos (directos e indirectos) serían coparticipados entre ambos niveles de gobierno.

De acuerdo al texto constitucional actual, el nivel federal tiene competencia exclusiva y permanente sobre los impuestos externos o aduaneros (arts. 4 y 75 , inc. $1^{\circ}$ ), como competencia concurrente con las provincias y de forma permanente los impuestos indirectos y de forma excepcional y transitoria, impuestos directos (art. 75 , inc. $2^{\circ}, 1^{\circ}$ párr.); las provincias por su parte tienen competencia exclusiva y permanente para establecer impuestos directos (art. 121) y de forma concurrente con el gobierno nacional, impuestos indirectos (art. 75 , inc. $2^{\circ}, 1^{\circ}$ párr.). En esta distribución de competencias no se hace referencia alguna a los municipios, aunque reconoce su autonomía económico-financiera en el art. 123 y la potestad impositiva de éstos en el art. 75, inc. 30. Sin embargo, de acuerdo a la distribución de competencias tributarias entre nación y provincias, podría interpretarse que a los municipios les corresponde, en principio, la misma competencia tributaria que las provincias, siendo las constituciones provinciales las que efectúen un deslinde más preciso de estas competencias, pero, aun así, tampoco existe un deslinde preciso de competencias tributarias entre provincias y municipios en las constituciones provinciales (Altavilla 2017b). A ello debe sumarse las limitaciones impuestas a la competencia tributaria provincial (y en consecuencia, a la municipal también) derivada de acuerdos y pactos interjurisdiccionales celebrados entre nación y provincias (verticales) o entre provincias (horizontales). Tales acuerdos generan una particular especie normativa cuyo rango constitucional es superior a las leyes nacionales y provinciales e integran lo 
que la Corte Suprema de Justicia de la Nación (CSJN) denominó "derecho intrafederal”6.

Sin entrar en un análisis particularizado de tan complejo sistema ${ }^{7}$, baste con decir que uno de estos acuerdos interjurisdiccionales, el Régimen de Coparticipación Federal de Impuestos, aprobado mediante Ley-Convenio $\mathrm{N}^{\circ} 23.548^{8}$ con vigencia desde 1988 establece que las provincias adheridas al régimen de distribución de recursos impositivos recaudados por el nivel nacional se obligan por sí, y a través de ellas, sus municipios, a no establecer impuestos análogos a los nacionales que integran este régimen (art. $9^{\circ}$, inc. g). Los impuestos nacionales que integran el fondo común son, de acuerdo al art. $2^{\circ}$, "todos los impuestos nacionales creados o a crearse". De esta manera, cerca del $80 \%$ de los impuestos vigentes en el país son sancionados y recaudados por el nivel federal, quedando solo cuatro impuestos en manos de las provincias $^{9}$. Como corolario, las provincias y en mayor medida los municipios, ven fuertemente restringida su competencia tributaria. Consecuencia de estas restricciones, los municipios en Argentina solo cuentan con tasas retributivas de servicios y contribuciones especiales (y dentro de ellas, particularmente, las contribuciones por mejoras) como los principales recursos genuinos. Dado el agotamiento de materias imponibles que pudieran estar sujetas a impuestos provinciales y/o municipales, los gobiernos locales solo podrían ejercer su poder impositivo sobre alguno de los cuatro impuestos que actualmente quedan en manos de las provincias.

Aun así, es posible observar que en solo 11 de las 23 provincias argentinas, los municipios recaudan impuestos sobre uno o algunos de los impuestos típicamente provinciales (ver TABLA 14), mientras en las restantes 12 provincias sus municipios no ejercen potestad impositiva alguna. Es decir, que en el $48 \%$ de las provincias los municipios ejercen efectivamente el poder de imposición (aunque muy limitado), mientras que en el otro $52 \%$ los municipios no establecen ningún tipo de impuestos (Altavilla 2017a y 2017b). Otra consecuencia de estas limitaciones es la fuerte dependencia de los presupuestos locales de recursos provenientes de otras jurisdicciones, tanto provincial como nacional y la escasa incidencia de los recursos propios, como puede observase en la TABLA 1. Esta estructura del financiamiento local caracterizada por la recentralización de recursos fiscales en manos del gobierno federal y la dependencia de los gobiernos subnacionales hacia aquellos recursos se replica en una primera instancia a nivel federal-provincias (Altavilla 2016), y luego a nivel provincias-municipios.

Por otro lado, si se analiza la legislación municipal en el país se puede observar la heterogeneidad que existe en el cobro de tributos que recaen sobre los más variados

\footnotetext{
${ }^{6}$ CSJN, "Transportes Automotores Chevallier S.A. c/Buenos Aires, Provincia de s/acción declarativa", del 20/08/1991, Fallos, 314:862 y más tarde en "El Cóndor Empresa de Transportes S.A. c/ Buenos Aires, Provincia de s/ acción declarativa", fallo del 7 de diciembre de 2001.

${ }^{7}$ Pueden consultarse Álvarez Echagüe 2000, Giuliani Fonrouge 2003 y Altavilla 2015.

${ }^{8}$ La denominada ley-convenio es una creación del derecho constitucional consuetudinario, consistente en la sanción de una ley federal a la cual después cada una de las provincias se adhieren, mediante respectivas leyes provinciales. En todos los casos, su sanción precedió a negociaciones entre los poderes ejecutivos provinciales y el poder ejecutivo nacional. Integran, junto con los pactos, acuerdo y tratados, el denominado derecho intrafederal.

${ }^{9}$ Estos son: impuesto automotor, inmobiliario, impuesto de sellos y el impuesto a los ingresos brutos.
} 
agentes económicos. La gran variedad de gravámenes que se detecta a nivel municipal ilustra la excesiva complejidad del esquema de financiamiento de los municipios en Argentina. En los mismos, una fuente de ingresos corresponde a recursos propios: cobro de tasas, contribuciones, patentes, multas, entre otros. Todos ellos caracterizados por el hecho de que su pago retribuye servicios prestados por parte del municipio - lo que no deja mayores márgenes para inversiones en otra áreas del gasto público que no sean aquellas actividades o materias gravadas por estas tasas. Del análisis de los ingresos totales obtenidos por el consolidado de municipios argentinos del año 2010, se observa que, aproximadamente, lo percibido en concepto de recursos propios alcanza a un $35 \%$. El $65 \%$ restante se integra por la coparticipación de impuestos nacionales y provinciales y transferencias de estas jurisdicciones (Argañaraz, Celdrán y D’Angelo 2012).

TABLA 1: ESTRUCTURA DE FINANCIAMIENTO DEL CONSOLIDADO MUNICIPAL ARGENTINO (2010)

\begin{tabular}{|l|r|}
\hline INGRESOS PROPIOS TRIBUTARIOS & $2,1 \%$ \\
\hline INGRESOS PROPIOS NO TRIBUTARIOS & $31,9 \%$ \\
\hline OTROS INGRESOS PROPIOS & $1,0 \%$ \\
\hline INGRESOS PROPIOS DE CAPITAL & $0,3 \%$ \\
\hline TOTAL INGRESOS PROPIOS & $\mathbf{3 5 , 3 \%}$ \\
\hline TRANSFERENCIAS DE CAPITAL & $13,0 \%$ \\
\hline TRANSFERENCIA CORRIENTES & $12,4 \%$ \\
\hline INGRESOS TRIBUTARIOS DE ORIGEN NACIONAL Y PROVINCIAL & $39,4 \%$ \\
\hline TOTAL INGRESOS DE NIVELES SUPERIORES DE GOBIERNO & $\mathbf{6 4 , 8 \%}$ \\
\hline
\end{tabular}

Fuente: Elaboración propia en base a datos obtenidos de Instituto Argentino de Análisis Fiscal (IARAF) y a información estadística de la Dirección Nacional de Coordinación Fiscal con las Provincias (DNCFP). Ministerio de Economía de la Nación.

Dentro del marco de la autonomía financiera los municipios pueden crear su estructura impositiva, pero las posibilidades de los mismos en cuanto al cobro de impuestos es diversa. En general, se puede concluir que por la incapacidad técnica y económica de los municipios para generar recursos propios y por los escasos niveles de coparticipación recibidos de las otras instancias de gobierno atentan contra las posibilidades de cumplir sus objetivos de gestión.

\section{El gasto municipal}

Tal como se lo expresara, el ejercicio de la autonomía posee una alta vinculación con la capacidad financiera de los municipios $y$, en general, la ciudadanía espera que los municipios resuelvan cuestiones que exceden su capacidad presupuestaria y que históricamente no se encontraban dentro de su campo de acción; situación que ha provocado que las decisiones de los intendentes se hayan complejizado respecto a la calidad y cantidad del gasto local. Tal como expresa Horacio Cao, la expectativa de los 
ciudadanos en cuanto al nivel de respuesta del municipio es bastante mayor que las competencias legales que poseen los mismos. En una encuesta realizada en el período 2004-2005 en doce provincias se atribuía a los gobiernos municipales tareas tradicionalmente a cargo de los niveles superiores de gobierno, como ser por ejemplo, obras de infraestructura y sistema jubilatorio (Cao 2007). Con respecto al análisis del gasto en el nivel local, se observa un panorama de bastante heterogeneidad, ya que en el sector municipal argentino se encuentran municipios grandes, medianos y chicos, ricos y pobres, urbanos y rurales, relacionados con actividades agropecuarias, industriales, de servicios, etcétera (Porto, Garriga y Rosales 2010).

Analizando las distancias que cada provincia tiene respecto del promedio nacional en lo relacionado a su gasto municipal per cápita $(\$ 3.345,36)$, Cao $(2007)$ ha agrupado las provincias en tres grupos:

1) Provincia de gasto alto, superior al $15 \%$ del promedio nacional, conformado por las provincias petroleras y algunas de la pampa húmeda: Córdoba, Chubut, La Pampa, Neuquén, La Rioja, Santa Cruz y Tierra del Fuego. En esta última el gasto municipal per cápita supera en un $300 \%$ al promedio nacional.

2) Provincias de gasto medio, ubicadas alrededor del promedio nacional, con diferencias que no superan el $15 \%$ y que agrupa a las provincias de San Juan, Río Negro, Jujuy, Buenos Aires, Entre Ríos, Catamarca y Santa Fe.

3) Provincias de gasto municipal bajo, por debajo del $15 \%$ del promedio nacional, entre las que se pueden mencionar Tucumán, Mendoza, Santiago del Estero, Chaco, San Luis, Salta, Formosa, Misiones y Corrientes. Estas tres últimas muestran una dispersión de alrededor del 50\% con respecto al promedio nacional.

Son evidentes las diferencias en el gasto municipal entre las provincias. Entre las causas podría pensarse en que, a mayores niveles de descentralización, mayor es el nivel de gasto local. Un ejemplo es la provincia de Neuquén, que coparticipa el $100 \%$ de sus recursos y se ubica en el tercer grupo, mientras que San Luis que pertenece al grupo de provincias con gasto municipal per cápita bajo, descentraliza alrededor del $7 \%$ de los ingresos. Otra causal se puede encontrar en la situación económica de los habitantes del municipio. Si el nivel de ingresos de los mismos es muy bajo, con necesidades básicas insatisfechas, la capacidad contributiva de los mismos será casi nula.

Atendiendo a las competencias que asumen los gobiernos locales, Cao (2007) expresa la existencia de una relación positiva entre el número de habitantes, su capacidad económica y la cantidad de funciones que los mismos asumen. A mayores niveles de respuesta de los municipios se tiende a generar entre sus habitantes expectativas por la resolución de problemáticas que deberían ser satisfechas por los niveles superiores de gobierno. Así, coexisten municipios cuyo papel continúa siendo el de prestadores de los servicios públicos tradicionales con otros que tienden a asumir funciones tales como el cuidado del medio ambiente, solución de problemáticas de salud, promoción del desarrollo endógeno, entre otras.

El análisis de los presupuestos locales arroja una elevada proporción de gastos corrientes, donde los salarios ocupan una proporción elevada de las erogaciones. Se observa también un alto nivel de gastos corrientes con proporciones reducidas de 
gastos de capital. En provincias como La Rioja y Catamarca el gasto en personal supera el $80 \%$, mientras que, en el otro extremo se observa San Luis donde se destina aproximadamente el $40 \%$ a estos conceptos.

Si se tiene en cuenta la naturaleza de los servicios prestados por los gobiernos municipales a la sociedad, los gastos se pueden estudiar desde la óptica del clasificador en "finalidad y funciones". De acuerdo a la TABLA 2 se puede observar la estructura de dicho gasto en el período 2006 a 2009. La mayor proporción del gasto local se destina a la provisión de servicios sociales. En el año 2009 dichas erogaciones ocupaban el 61\% del total de gastos. El destino de estos gastos en general ha sido en: (a) promoción y asistencia social: servicios de protección y ayuda a personas necesitadas a través de aportes financieros y entrega de ropa, víveres, alojamiento y/o manutención; acciones destinadas a organismos sociales y comunitarios para que tengan medios para cumplir sus actividades de desarrollo social o bien público; actividades promocionales de los deportes y cultura física; gastos para actividades de esparcimiento de la población; (b) los servicios urbanos que satisfacen necesidades colectivas de carácter local, tales como alumbrado, limpieza, conservación de la vía pública, recolección y tratamiento de los residuos domiciliarios, etcétera; y (c) servicios municipales de salud y educación.

La proporción de los gastos en promoción y asistencia social se ha elevado considerablemente: desde un $6 \%$ en 1980, alcanzaron en 2009 el 22,40\%. El gasto en salud pública ha tenido un comportamiento similar. En líneas generales son los gastos de promoción y asistencia social los que han ganado participación en la estructura del gasto público social. Con respecto a la tendencia del gasto público social en el periodo seleccionado se observa que ante un incremento en el total de un $99,81 \%$, las erogaciones en promoción y asistencia social han crecido un $119,94 \%$. El incremento de los otros gastos sociales, como salud y educación básica, ha rondado el $91 \%$. La selección del período de análisis responde a que en el año 2006 se tomó la encuesta que sustenta este trabajo, contándose con datos sobre este tópico sólo hasta el 2009.

TABLA 2: GASTO PÚBLICO MUNICIPAL EN ARGENTINA. CONSOLIDADO PERÍODO $2006 / 2009$

\begin{tabular}{|c|c|c|c|c|c|c|c|c|}
\hline FINALIDAD / FUNCION & 2006 & Estructura & 2007 & \begin{tabular}{|l|} 
Estructura \\
\end{tabular} & 2008 & Estructura & 2009 & Estructura \\
\hline GASTO TOTAL & 18.946 & 100.00 & 23.545 & 100.00 & 30.322 & 100.00 & 37.133 & 100.00 \\
\hline $\begin{array}{l}\text { I. FUNCIONAMIENTO DEL } \\
\text { ESTADO }\end{array}$ & 6.003 & 31.68 & 7.606 & 32.30 & 9.773 & 32.23 & 11.468 & 30.88 \\
\hline I.1. Administración general & 6.003 & & 7.606 & & 9.773 & & 11.468 & \\
\hline I.2. Justicia & & & & & & & & \\
\hline I.3. Defensa y seguridad & & & & & & & & \\
\hline II. GASTO PUBLICO SOCIAL & 11.417 & 60.26 & 14.046 & 59.66 & 18.106 & 59.71 & 22.812 & 61.43 \\
\hline $\begin{array}{l}\text { II.1. Educación, cultura y } \\
\text { ciencia y técnica }\end{array}$ & 912 & 4.81 & 1.151 & 4.89 & 1.486 & 4.90 & 1.741 & 4.69 \\
\hline
\end{tabular}




\begin{tabular}{|c|c|c|c|c|c|c|c|c|}
\hline II.1.1. Educación básica & 912 & & 1.151 & & 1.486 & & 1.741 & \\
\hline $\begin{array}{l}\text { II.1.2. Educación superior y } \\
\text { universitaria }\end{array}$ & & & & & & & & \\
\hline II.1.3. Ciencia y técnica & & & & & & & & \\
\hline II.1.4. Cultura & & & & & & & & \\
\hline $\begin{array}{l}\text { Il.1.5. Educación y cultura sin } \\
\text { discriminar }\end{array}$ & & & & & & & & \\
\hline II.2. Salud & 2.070 & 10.92 & 2.618 & 11.12 & 3.415 & 11.26 & 3.996 & 10.76 \\
\hline $\begin{array}{l}\text { II.2.1. Atención pública de la } \\
\text { salud }\end{array}$ & 2.070 & & 2.618 & & 3.415 & & 3.996 & \\
\hline $\begin{array}{l}\text { II.2.2. Obras sociales - } \\
\text { Atención de la salud }\end{array}$ & & & & & & & & \\
\hline $\begin{array}{l}\text { II.2.3. INSSJyP - Atención de la } \\
\text { salud }\end{array}$ & & & & & & & & \\
\hline $\begin{array}{lrr}\text { Il.3. Agua } & \text { potable } & \text { y } \\
\text { alcantarillado } & & \end{array}$ & & & & & & & & \\
\hline II.4. Vivienda y urbanismo & & & & & & & & \\
\hline $\begin{array}{l}\text { II.5. Promoción y asistencia } \\
\text { social }\end{array}$ & 3.781 & 19.96 & 4.403 & 18.70 & 5.622 & 18.54 & 8.316 & 22.40 \\
\hline $\begin{array}{l}\text { II.5.1. Promoción y asistencia } \\
\text { social pública }\end{array}$ & 3.781 & & 4.403 & & 5.622 & & 8.316 & \\
\hline $\begin{array}{ll}\text { II.5.2. Obras sociales - } \\
\text { Prestaciones sociales }\end{array}$ & & & & & & & & \\
\hline $\begin{array}{l}\text { II.5.3. INSSJyP - Prestaciones } \\
\text { sociales }\end{array}$ & & & & & & & & \\
\hline II.6. Previsión social & & & & & & & & \\
\hline II.7. Trabajo & & & & & & & & \\
\hline $\begin{array}{l}\text { II.7.1. Programas de empleo y } \\
\text { seguro de desempleo }\end{array}$ & & & & & & & & \\
\hline II.7.2. Asignaciones familiares & & & & & & & & \\
\hline II.8. Otros servicios urbanos & 4.653 & 24.55 & 5.874 & 24.95 & 7.582 & 25 & 8.759 & 23.59 \\
\hline $\begin{array}{lcc}\text { III. GASTO PUBLICO } & \text { EN } \\
\text { SERVICIOS ECONOMICOS } & \\
\end{array}$ & 1.438 & 7.60 & 1.784 & 7.58 & 2.304 & 7.60 & 2.664 & 7.18 \\
\hline III.1. Producción primaria & & & & & & & & \\
\hline III.2. Energía y combustible & 10 & & 7 & & 21 & & 22 & \\
\hline III.3. Industria & 26 & & 33 & & 43 & & 49 & \\
\hline III.4. Servicios & 1.205 & & 1.483 & & 1.893 & & 2.195 & \\
\hline III.4.1. Transporte & 1.205 & & 1.483 & & 1.893 & & 2.195 & \\
\hline III.4.2. Comunicaciones & & & & & & & & \\
\hline $\begin{array}{l}\text { III.5. Otros gastos en servicios } \\
\text { económicos }\end{array}$ & 197 & & 262 & & 347 & & 398 & \\
\hline $\begin{array}{l}\text { IV. SERVICIOS DE LA DEUDA } \\
\text { PUBLICA }\end{array}$ & 87 & 0.46 & 108 & 0.46 & 139 & 0.046 & 188 & 0.51 \\
\hline
\end{tabular}


Elaboración propia en base a datos de la Dirección de Análisis de Gasto Público y Programas Sociales.- Secretaría de Política Económica. 


\section{La agenda municipal}

Si los municipios tienen dificultades en la generación de los propios recursos y dependen de la coparticipación y de las transferencias de los niveles superiores de gobierno, ven limitado el ejercicio efectivo de su autonomía aun cuando las constituciones provinciales la reconozcan expresamente. La construcción de la agenda por parte de los intendentes se verá influenciada por las limitaciones en la autonomía financiera. Además la existencia de normas constitucionales y legales y el accionar de quienes actúan en los otros niveles gubernamentales incidirán en las decisiones sobre políticas públicas, como así también la relación con la diversidad de actores locales.

A continuación se analizarán las respuestas de los intendentes a preguntas de la encuesta Fiscal Austerity and Urban Innovation (F.A.U.I.) relevada en nuestro país en municipios mayores de diez mil habitantes, para intentar conocer las preferencias de los mismos en el diseño de las políticas públicas y la influencia de actores institucionales y locales en dicha tarea. Mediante las tablas que siguen se trata de evaluar las preferencias en el gasto de los intendentes. Se han considerado aquellas decisiones relacionadas con mejorar las condiciones de vida de la población, o sea de tipo social, y otras que tienden a contribuir al crecimiento económico de la comunidad $^{10}$.

\subsection{Políticas sociales}

TABLA 3: PREFERENCIA EN EL GASTO DEL GOBIERNO MUNICIPAL: POLÍTICA SOCIAL (ASISTENCIA A POBRES, ETC.). AÑO 2006

\begin{tabular}{|l|l|l|l|l|l|}
\hline \multicolumn{2}{|c|}{} & Frecuencia & Porcentaje & $\begin{array}{l}\text { Porcentaje } \\
\text { válido }\end{array}$ & $\begin{array}{l}\text { Porcentaje } \\
\text { acumulado }\end{array}$ \\
\hline Válidos & Gastar mucho menos & 1 & 1,1 & 1,1 & 1,1 \\
& Un poco menos & 7 & 7,4 & 7,9 & 9,0 \\
& Lo mismo & 31 & 33,0 & 34,8 & 43,8 \\
& Un poco mas & 37 & 39,4 & $\mathbf{4 1 , 6}$ & 85,4 \\
& Gastar mucho mas & 13 & 13,8 & $\mathbf{1 4 , 6}$ & 100,0 \\
\cline { 2 - 7 } & Total & 89 & 94,7 & 100,0 & \\
\cline { 2 - 7 } & No Responde & 5 & 5,3 & & \\
\hline Total & 94 & 100,0 & & \\
\hline
\end{tabular}

Fuente: Elaboración propia en base a información obtenida de la Encuesta del Proyecto Internacional F.A.U.I..

De las respuestas obtenidas, el 56,20\% de los intendentes manifiesta la necesidad de incrementar los gastos para mejorar las condiciones de vida de las familias que viven en situación de precariedad y con problemas laborales. Estas actividades se desarrollan

\footnotetext{
${ }^{10}$ La pregunta era: Para las siguientes áreas de políticas públicas, ¿cómo prefiere Ud. que se gaste el presupuesto del gobierno municipal, indicando si se debe gastar mucho menos o mucho más? Una respuesta para cada área. Si es un área que no atiende el municipio, marque "no aplicable".
} 
con ciertos sesgos asistencialistas y no han logrado una integración adecuada de este segmento de la población local.

TABLA 4: PREFERENCIA EN EL GASTO DEL GOBIERNO MUNICIPAL: SALUD PÚBLICA, SALAS SANITARIAS U HOSPITALES. AÑO 2006

\begin{tabular}{|ll|l|l|l|l|}
\hline & Frecuencia & Porcentaje & $\begin{array}{l}\text { Porcentaje } \\
\text { válido }\end{array}$ & $\begin{array}{l}\text { Porcentaje } \\
\text { acumulado }\end{array}$ \\
\hline Válidos & Lo mismo & 14 & 14,9 & 21,5 & 21,5 \\
& Un poco mas & 33 & 35,1 & $\mathbf{5 0 , 8}$ & $\mathbf{7 2 , 3}$ \\
& Gastar mucho mas & 18 & 19,1 & $\mathbf{2 7 , 7}$ & 100,0 \\
& Total & 65 & 69,1 & 100,0 & \\
& No Responde & 6 & 6,4 & & \\
& No aplicable & 23 & 24,5 & & \\
Total & 29 & 30,9 & & \\
\hline
\end{tabular}

Fuente: Elaboración propia en base a información obtenida de la Encuesta del Proyecto Internacional F.A.U.I..

Si bien el $24,5 \%$ de los intendentes las considera no aplicables, del $70 \%$ de las respuestas válidas, el 78,5\% considera que hay que gastar más. Es un servicio que en general es prestado por el nivel provincial, por el efecto derrame que genera.

TABLA 5: PREFERENCIA EN EL GASTO DEL GOBIERNO MUNICIPAL: VIVIENDAS PARA SECTORES DE BAJOS RECURSOS. AÑO 2006

\begin{tabular}{|ll|l|l|l|l|}
\hline & Frecuencia & Porcentaje & $\begin{array}{l}\text { Porcentaje } \\
\text { válido }\end{array}$ & $\begin{array}{l}\text { Porcentaje } \\
\text { acumulado }\end{array}$ \\
\hline Válidos & Lo mismo & 11 & 11,7 & 14,5 & 14,5 \\
& Un poco mas & 31 & 33,0 & $\mathbf{4 0 , 8}$ & 55,3 \\
Gastar mucho mas & 34 & 36,2 & $\mathbf{4 4 , 7}$ & 100,0 \\
Total & 76 & 80,9 & 100,0 & \\
No Responde & 6 & 6,4 & & \\
No aplicable & 12 & 12,8 & & \\
Total & 18 & 19,1 & & \\
\hline
\end{tabular}

Fuente: Elaboración propia en base a información obtenida de la Encuesta del Proyecto Internacional F.A.U.I..

El $85,5 \%$ de los intendentes consideran que es un gasto que hay que aumentar. Estas políticas forman parte de políticas en cuya implementación se observan tintes de asistencialismo. 
TABLA 6: PREFERENCIA EN EL GASTO DEL GOBIERNO MUNICIPAL: OBRAS PÚBLICAS (CALLES, ALUMBRADO, ESTACIONAMIENTO). AÑO 2006

\begin{tabular}{|ll|l|l|l|l|}
\hline & Frecuencia & Porcentaje & $\begin{array}{l}\text { Porcentaje } \\
\text { válido }\end{array}$ & $\begin{array}{l}\text { Porcentaje } \\
\text { acumulado }\end{array}$ \\
\hline Válidos & Gastar mucho & 1 & 1,1 & 1,1 & 1,1 \\
& menos & & & \\
& Un poco menos & 1 & 1,1 & 1,1 & 2,2 \\
& Lo mismo & 8 & 8,5 & 9,0 & 11,2 \\
& Un poco mas & 35 & 37,2 & 39,3 & 50,6 \\
& Gastar mucho mas & 44 & 46,8 & 49,4 & 100,0 \\
& Total & 89 & 94,7 & 100,0 & \\
No Responde & 5 & 5,3 & & \\
\hline
\end{tabular}

Fuente: Elaboración propia en base a información obtenida de la Encuesta del Proyecto Internacional F.A.U.I..

Esta función tiene una preferencia elevada ya que, mientras que el 39,3\% opina que "hay que gastar un poco más", el $49,4 \%$ considera que hay que gastar mucho más. Si bien el financiamiento proviene de las esferas superiores de gobierno, la gestión de las obras es realizada por la comuna. De ahí el interés en este tipo de políticas para una buena apreciación de la gestión local.

TABLA NNo 7: PREFERENCIA EN EL GASTO DEL GOBIERNO MUNICIPAL: BARRIDO, LIMPIEZA Y RECOGIDA DE BASURA. AÑO 2006

\begin{tabular}{|c|c|c|c|c|c|}
\hline & & Frecuencia & Porcentaje & $\begin{array}{l}\text { Porcentaje } \\
\text { válido }\end{array}$ & $\begin{array}{l}\text { Porcentaje } \\
\text { acumulado }\end{array}$ \\
\hline \multirow[t]{6}{*}{ Válidos } & Un poco menos & 6 & 6,4 & 6,7 & 6,7 \\
\hline & Lo mismo & 29 & 30,9 & 32,6 & 39,3 \\
\hline & Un poco mas & 32 & 34,0 & 36,0 & 75,3 \\
\hline & Gastar mucho mas & 22 & 23,4 & 24,7 & 100,0 \\
\hline & Total & 89 & 94,7 & 100,0 & \\
\hline & No Responde & 5 & 5,3 & & \\
\hline Total & & 94 & 100,0 & & \\
\hline
\end{tabular}

Fuente: Elaboración propia en base a información obtenida de la Encuesta del Proyecto Internacional F.A.U.I..

Es una función tradicional y básica en los municipios. Los intendentes consideran, en el $60,7 \%$ de los casos, que el gasto se debe aumentar.

TABLA 8: PREFERENCIA EN EL GASTO DEL GOBIERNO MUNICIPAL: PARQUES Y ÁREAS 


\begin{tabular}{|ll|l|l|l|l|}
\hline & Frecuencia & Porcentaje & $\begin{array}{l}\text { Porcentaje } \\
\text { válido }\end{array}$ & $\begin{array}{l}\text { Porcentaje } \\
\text { acumulado }\end{array}$ \\
\hline Válidos & Un poco menos & 2 & 2,1 & 2,3 & 2,3 \\
& Lo mismo & 28 & 29,8 & 31,8 & 34,1 \\
Un poco mas & 38 & 40,4 & $\mathbf{4 3 , 2}$ & 77,3 \\
Gastar mucho mas & 20 & 21,3 & $\mathbf{2 2 , 7}$ & 100,0 \\
Total & 88 & 93,6 & 100,0 & \\
& No Responde & 5 & 5,3 & & \\
& No aplicable & 1 & 1,1 & & \\
Total & 6 & 6,4 & & \\
\hline
\end{tabular}

Fuente: Elaboración propia en base a información obtenida de la Encuesta del Proyecto Internacional F.A.U.I..

Los intendentes se manifiestan bastante conservadores en el monto a gastar en este ítem, ya que sólo alrededor del $22,7 \%$ consideran que hay que gastar mucho más. Es un gasto que se ve y mejora la imagen de la ciudad, contribuyendo al bienestar de la ciudadanía.

\section{4-2: Políticas para el desarrollo económico}

TABLA 9: PREFERENCIA EN EL GASTO DEL GOBIERNO MUNICIPAL: INFRAESTRUCTURA PARA RADICAR EMPRESAS. AÑO 2006

\begin{tabular}{|c|c|c|c|c|c|}
\hline & & Frecuencia & Porcentaje & $\begin{array}{l}\text { Porcentaje } \\
\text { válido }\end{array}$ & $\begin{array}{l}\text { Porcentaje } \\
\text { acumulado }\end{array}$ \\
\hline \multirow[t]{8}{*}{ Válidos } & Un poco menos & 1 & 1,1 & 1,1 & 1,1 \\
\hline & Lo mismo & 8 & 8,5 & 9,2 & 10,3 \\
\hline & Un poco mas & 47 & 50,0 & 54,0 & 64,4 \\
\hline & Gastar mucho mas & 31 & 33,0 & 35,6 & 100,0 \\
\hline & Total & 87 & 92,6 & 100,0 & \\
\hline & No Responde & 4 & 4,3 & & \\
\hline & No aplicable & 3 & 3,2 & & \\
\hline & Total & 7 & 7,4 & & \\
\hline Total & & 94 & 100,0 & & \\
\hline
\end{tabular}

Fuente: Elaboración propia en base a información obtenida de la Encuesta del Proyecto Internacional F.A.U.I..

Para el logro de un desarrollo endógeno es fundamental la relación entre el gobierno municipal y las empresas, de ahí que facilitar los procesos de radicación de empresas en el territorio es percibido por los intendentes como muy importante, ya que el $89,6 \%$ 
de los encuestados coincidió en que hay que gastar más, de los cuales un $54,0 \%$ consideró gastas más y un 35,6\% mucho más.

TABLA No 10: PREFERENCIA EN EL GASTO DEL GOBIERNO MUNICIPAL: PROTECCIÓN DEL MEDIO AMBIENTE. AÑO 2006

\begin{tabular}{|ll|l|l|l|l|}
\hline & Frecuencia & Porcentaje & $\begin{array}{l}\text { Porcentaje } \\
\text { válido }\end{array}$ & $\begin{array}{l}\text { Porcentaje } \\
\text { acumulado }\end{array}$ \\
\hline Válidos & Gastar mucho & 2 & 2,1 & 2,3 & 2,3 \\
menos & 1 & 1,1 & 1,2 & 3,5 \\
Un poco menos & 13 & 13,8 & 15,1 & 18,6 \\
Lo mismo & 37 & 39,4 & $\mathbf{4 3 , 0}$ & 61,6 \\
Un poco mas & 33 & 35,1 & $\mathbf{3 8 , 4}$ & 100,0 \\
Gastar mucho mas & 86 & 91,5 & 100,0 & \\
Total & 5 & 5,3 & & \\
No Responde & 3 & 3,2 & & \\
No aplicable & 8 & 8,5 & & \\
Total & 94 & 100,0 & & \\
Total &
\end{tabular}

Fuente: Elaboración propia en base a información obtenida de la Encuesta del Proyecto Internacional F.A.U.I..

El desarrollo debe ser sustentable, por ello la cuestión ambiental es fundamental. El $81,4 \%$ de los intendentes manifiestan la necesidad de aumentar el gasto en lo ambiental, sea un poco más $(43,0 \%)$ o mucho más $(38,4 \%)$. Se debe considerar que este tema genera "dividendos dobles": a través de multas o impuestos se pueden generar recursos para el municipio.

TABLA 11: PREFERENCIA EN EL GASTO DEL GOBIERNO MUNICIPAL: TECNOLOGÍAS PARA LA MODERNIZACIÓN DE LA GESTIÓN. AÑO 2006

\begin{tabular}{|c|c|c|c|c|c|}
\hline & & Frecuencia & Porcentaje & $\begin{array}{l}\text { Porcentaje } \\
\text { válido }\end{array}$ & $\begin{array}{l}\text { Porcentaje } \\
\text { acumulado }\end{array}$ \\
\hline \multirow[t]{6}{*}{ Válidos } & No Responde & 5 & 5,3 & 5,3 & 5,3 \\
\hline & Un poco menos & 1 & 1,1 & 1,1 & 6,4 \\
\hline & Lo mismo & 10 & 10,6 & 10,6 & 17,0 \\
\hline & Un poco mas & 51 & 54,3 & 54,3 & 71,3 \\
\hline & Gastar mucho mas & 27 & 28,7 & 28,7 & 100,0 \\
\hline & Total & 94 & 100,0 & 100,0 & \\
\hline
\end{tabular}

Fuente: Elaboración propia en base a información obtenida de la Encuesta del Proyecto Internacional F.A.U.I.. 
Por último es interesante conocer la intención de gastar de los intendentes en la mejora de las tecnologías de gestión, ya que para poder cumplir con las nuevas competencias locales, es necesaria la transformación de los estilos y formas de gobernar. La respuesta de los intendentes es, en un $83 \%$, gastar más en este campo.

\section{La influencia de los actores institucionales y locales:}

Es interesante analizar también la influencia de los actores locales e institucionales en las decisiones de gasto de los intendentes. Entre estos grupos, aquellos que tratan de que el gasto público se oriente de acuerdo a sus intereses son considerados por los intendentes como más activos: Con ellos se relacionan con más frecuencia para la implementación de las distintas políticas públicas.

TABLA 12: ¿CUÁN ACTIVOS HAN SIDO LOS SIGUIENTES ACTORES Y GRUPOS PARA LOGRAR QUE SE GASTE DE ACUERDO CON SUS INTERESES? (EN \%). AÑO 2006

\begin{tabular}{|l|l|l|l|l|l|}
\hline ACTORES & $\begin{array}{l}\text { Más } \\
\text { activo } \\
\text { de todos }\end{array}$ & $\begin{array}{l}\text { Muy } \\
\text { activo }\end{array}$ & $\begin{array}{l}\text { Algo } \\
\text { activo }\end{array}$ & $\begin{array}{l}\text { Poco } \\
\text { activo }\end{array}$ & $\begin{array}{l}\text { Nada } \\
\text { activo }\end{array}$ \\
\hline $\begin{array}{l}\text { Organizaciones interesadas en grupos } \\
\text { de bajos recursos }\end{array}$ & 2,1 & 23,6 & 41,5 & 17 & 11,7 \\
\hline Dirigentes barriales & 5,3 & 34 & 39,4 & 14,9 & 1,1 \\
\hline Asociaciones o grupos de vecinos & 2,1 & 30,9 & 43,6 & 13,8 & 6,4 \\
\hline Movimientos de desocupados & 1,1 & 13,8 & 21,3 & 23,4 & 17,0 \\
\hline Grupos cívicos & 1,1 & 11,2 & 30,3 & 34,8 & 14,6 \\
\hline $\begin{array}{l}\text { Clubes deportivos o asociaciones } \\
\text { culturales }\end{array}$ & 0,0 & 24,7 & 47,2 & 20,2 & 3,4 \\
\hline Empresarios y sus asociaciones & 3,4 & 21,3 & 38,2 & 15,7 & 15,7 \\
\hline Asociaciones ecologistas & 0,0 & 11,7 & 25,5 & 26,6 & 14,9 \\
\hline El gobierno nacional & 1,1 & 24,7 & 29,2 & 19,1 & 20,2 \\
\hline El gobierno provincial & 3,2 & 27,7 & 27,7 & 18,1 & 13,8 \\
\hline El gobernador de la provincia & 6,4 & 30,9 & 23,4 & 14,9 & 18,1 \\
\hline
\end{tabular}

Fuente: Elaboración propia en base a información obtenida de la Encuesta del Proyecto Internacional F.A.U.I..

Las relaciones de los intendentes se pueden analizar en un sentido vertical: son las que resultan de la interacción con los otros niveles de gobierno, sobre todo el provincial. Estas relaciones pueden adoptar dos tipos de modalidades (siguiendo a Weber 1974): (a) estamental, cuando los intendentes son delegados que representan al gobernador y a él le deben la legitimidad de su mandato y (b) feudal, caso en que se establecen alianzas políticas mediante pactos que se originan en relaciones de vasallaje entre señores. En un sentido localista u horizontal se intenta medir las relaciones que se generan entre el intendente y los diversos actores locales. 
En la TABLA 12 se refleja la percepción de los intendentes respecto de cómo incide la influencia de los actores locales sobre sus decisiones de gasto. Con respecto a los niveles de influencia, analizándolo desde el enfoque horizontal, se puede inferir que, para los intendentes, son percibidos como muy activos aquellos grupos cuyos intereses se relacionan con las actividades de promoción y asistencia social, como ser por ejemplo organizaciones interesadas en grupos de bajos recursos, grupos o asociaciones vecinales o dirigentes barriales. En estos casos el nivel de influencia es elevado: fluctúa alrededor del 70\%, entre "algo activo" y "muy activo". En el caso de los dirigentes barriales, su tipo de participación reviste ciertas características ya que cumplen un rol de mediadores entre el ciudadano y el intendente. Es la figura del "guardabarreras" (Auyero 2001), considerado como muy activo con el 34\%.

Con respecto al caso de los movimientos de desocupados, se reconoce un bajo nivel de influencia, sólo en el $13,8 \%$ los jefes comunales los consideran muy activos. Ello puede explicarse por el hecho de que la política laboral se encuentra concentrada más en el nivel federal y en los provinciales secundariamente, y no tanto a nivel municipal (aun cuando las constituciones les reconocen competencia en esta materia) y la percepción de la población tiende a identificar esta política con aquellos niveles superiores más que con los locales.

Referido a la influencia que se reconoce a asociaciones y grupos empresarios, que podemos relacionar con las políticas referidas al desarrollo económico local, se observa que los intendentes los consideran como "muy activos" en el $21,30 \%$ de los casos. A pesar del aumento en el ámbito local del interés por lo ambiental reflejado en las preferencias de gasto de los intendentes, la influencia que reconocen de las asociaciones ecologistas es muy baja: en un $11,7 \%$ de los casos los reconocen como muy activos y en el $67 \%$ poco influyentes. Ello puede interpretarse en el sentido de que la cuestión ecológica no ha llegado a tener el impacto esperado, en términos generales, en nuestro país y mucho menos a nivel municipal. Un claro ejemplo de ello es la cuestión de la tributación ambiental, materia que en países como España y los escandinavos ha alcanzado en la actualidad mucho desarrollo. Es posible interpretar que la cuestión ecológica resulta muy incipiente aún y que no existe un marco jurídico ni una política global encarada desde los niveles superiores que permita a los gobiernos locales y a las distintas asociaciones relacionadas con la temática llevar adelante políticas concretas sobre la materia. Asimismo, es de observar que si bien existe una preferencia por aumentar el gasto en lo ambiental, ello no se ve reflejado en los presupuestos locales ni siquiera provinciales.

Si el análisis se refiere a las relaciones con los otros niveles de gobierno es observable que la figura que consideran más influyente en las decisiones de gasto es la del gobernador de la provincia: "muy activo" en el 30,9\% de los casos, mientras que con el gobierno provincial el porcentaje es del $27,7 \%$. La figura del gobernador de provincia aparece así, junto con las asociaciones de vecinos, como el actor más activo para lograr que se gaste de acuerdo con sus intereses. Ello no es de extrañar dada la gran injerencia que ejercen los gobernadores (sea directamente o a través de agencias del Estado provincial) sobre los gobiernos municipales y la dependencia de éstos hacia los recursos provinciales. El accionar de los municipios afectado generalmente por las limitaciones presupuestarias ocasiona una gran dependencia hacia los otros niveles gubernamentales. 
Es así que en los tres casos (el gobierno nacional, el gobierno provincial y el gobernador) su consideración como actores algo activos, muy activos y más activos de todos, resulta evidente por la dependencia económica de los municipios hacia estos dos niveles de gobierno. Pero de entre ellos, resalta la figura del gobernador como el actor más activo entre los actores que ejercen algún tipo de influencia sobre los gobiernos municipales. Como puede observarse en la TABLA $\mathrm{N}^{\circ} 12$, la figura del gobernador alcanza el máximo porcentaje entre todos los actores en el ítem "actor más activo de todos".

\section{Gobiernos locales, decisiones y gasto público}

Analizar las relaciones que se generan en el ámbito municipal es una tarea compleja, ya que los gobiernos locales han comprendido la importancia de crear espacios participativos que permitan la realización de actividades conjuntas entre ciudadanos, organizaciones de la sociedad civil, empresas y otros para poder dar respuesta a competencias cada vez más complejas que deben asumir.

Dentro del escaso margen que el gasto y los recursos municipales representan en el total consolidado del país, es posible observar que en el período 2006 a 2009 los gastos que más han aumentado son los de Promoción y Asistencia Social, mientras que los relacionados con los servicios económicos han permanecido estables a lo largo del tiempo. Si se comparan estos datos con las preferencias de gasto de los intendentes, se puede inferir la elección de políticas destinadas a satisfacer las demandas sociales por sobre las que se relacionan con el crecimiento económico. En concordancia con ello, Saunders (1981, citado por Cáceres 2008) sostiene que son los niveles centrales quienes se especializan en políticas orientadas a la inversión y los niveles locales a las políticas sociales, sin embargo, como las políticas sociales están siempre subordinadas a las de inversión y las definiciones estratégicas se desarrollan en el centro, las instancias locales permanecen en consecuencia al margen de las definiciones de la agenda estratégica y tiene escasas posibilidades de influencia en la definición de los proyectos políticos dominantes (Cáceres 2008:6).

Aun así es notable observar cómo los intendentes se muestran propensos a aumentar el gasto en prácticamente todos los ítems. Como se observa en las TABLAS 3 a 11, la gran mayoría de los intendentes prefieren aumentar el gasto (sea un poco más o mucho más) en cada una de las políticas propuestas ${ }^{11}$. Ello puede ser entendido como consecuencia de dos fenómenos muy propios de sistemas federales o fiscalmente descentralizados: por un lado, la existencia de comportamientos que se corresponden con lo que la literatura del federalismo fiscal ha denominado como problemas de pool común (common pool problem). Al ser el gobierno central el nivel que concentra en su jurisdicción la mayor recaudación tributaria y el que maneja un mayor volumen de recursos que luego han de ser distribuidos al conjunto de los gobiernos subnacionales, el costo de oportunidad de generar aquellos ingresos no es percibido con el verdadero costo social que en la realidad tienen (Altavilla 2016a) y de ahí que la preferencia a

\footnotetext{
${ }^{11}$ Un $56 \%$ en política social; el $78 \%$ en salud pública, el $85 \%$ en vivienda, el $89 \%$ en obras públicas; el $61 \%$ en barrido y limpieza; el $65 \%$ en parques y áreas recreativas; el $90 \%$ en infraestructura; el $81 \%$ en medio ambiente; y el $83 \%$ en modernización de la gestión.
} 
aumentar el gasto sea natural en estos entes subnacionales. Por otro lado, puede observarse también que una de las consecuencias de los procesos de descentralización en Argentina (e incluso en el resto de la región) fue la redefinición del rol de cada nivel de gobierno en la provisión de servicios básicos, donde el nivel central se reservó la función de financiación (centralización de recursos fiscales) y los entes subnacionales la de implementación (descentralización de funciones), predeterminando de esta manera un rol de ahorrador en el primero y de gastadores en los segundos (BlomHansen 1999). En concordancia con la afirmación de Saunders (1981), la estructura federal otorga distintos incentivos a los diferentes niveles de gobierno en orden al gasto: el gobierno nacional, responsable de la economía nacional, tendrá incentivos hacia la prudencia y la austeridad en el gasto, sobre todo a través del control fiscal (Jones, Sanguinetti y Tommasi 1997); los niveles subcentrales, en cambio, tienen mayores incentivos hacia el gasto y la consecución de mayores recursos sin realizar el esfuerzo fiscal necesario para ello.

Los municipios, aunque detenten autonomía plena, en todos los órdenes, se ven afectados por las limitaciones en el aspecto financiero de esa autonomía. En efecto, es posible observar una importante brecha entre las disposiciones constitucionales que hacen al diseño institucional de los gobiernos locales en Argentina y el funcionamiento efectivo de estos niveles. Como se señaló anteriormente, la dependencia de las provincias y de los municipios hacia los recursos de origen nacional es muy elevada, incluso comparando con países de estructura unitaria, aunque altamente descentralizado, como sucede con los países escandinavos (Altavilla 2016b).

La falta de autonomía en este aspecto no solo afecta, como se sostuvo anteriormente, la gestión municipal, sino que también dejan espacio suficiente para la generación y proliferación de prácticas poco democráticas. Así, en escenarios donde la autonomía es más formal que efectiva, resulta expectable que el ejercicio de gobernar adopte modalidades casi feudales: el amiguismo, el clientelismo, el prebendarismo resultan prácticas expectables en estos contextos. El predominio de instituciones informales en el relacionamiento entre niveles de gobierno que llegan incluso a sustituir instituciones formales, es una clara característica del sistema fiscal argentino y ello puede ser visto como un factor que incentiva comportamientos oportunistas y clientelares entre los actores gubernamentales implicados (Altavilla 2016a). Entre estas características se encuentran la discrecionalidad en la distribución de fondos, lo que a su vez genera espacio, en última instancia, a un mayor "clientelismo regional" (Rodden 2009) en el federalismo fiscal argentino, fácilmente observable en el nivel municipal si se compara el porcentaje que los recursos de jurisdicción ajena (nacional y provincial) representan en los presupuestos municipales. A ello cabe agregar las características del sistema de partidos y la forma de gobierno presidencialista, que en conjunto "generan un estilo de construcción de coaliciones caracterizadas por un clientelismo político regional y que hacen que las transferencias progresivas sean un resultado poco probable" (Rodden 2009:193). Una consecuencia directa de ello es que en las relaciones de los intendentes con niveles superiores de gobierno, los primeros suelen mostrarse como delegados de estas instancias supraordenadas, donde su capacidad política y negociadora se ve muy limitada. En contrapartida, funcionarios de los niveles superiores, por lo general, ven a los municipios como entes más autárquicos que autónomos, como meros ejecutores de sus políticas. En este contexto, resulta 
esperable un nivel de gobierno local que se limita a aplicar políticas impuestas por los niveles superiores, de acuerdo a sus propias preferencias, más que entes autónomos y genuinos promotores del desarrollo local según las preferencias de los actores políticos y sociales de la comunidad.

\section{A modo de conclusiones preliminares}

En función de lo analizado en este trabajo, es posible arribar a dos conclusiones (que no dejan de ser preliminares en esta fase de la investigación): por un lado, la desvinculación entre los diseños institucionales y las capacidades reales de los municipios para construir sus propias agendas y, en función de ellas, su posibilidad de dar respuestas eficientes a las problemáticas que la sociedad actual les plantea y que los diseños constitucionales e institucionales ponen en manos de los gobiernos locales; por otro lado, resulta también necesario efectuar un balance de la literatura actual sobre la temática de los gobiernos locales en el que se ponga de manifiesto sus aportes y, a raíz de ellos, posibles futuras líneas de investigación.

\subsection{El diseño institucional y las capacidades reales de los municipios para construir agendas propias}

En paralelo al aumento de las competencias municipales, dos variables han permanecido constantes en este proceso de descentralización y de asignación de nuevos roles que atentaron (y continúan atentando) contra el rol del municipio como gestor de políticas sociales y de desarrollo, limitando en consecuencia su poder de decisión: la ausencia de financiamiento (sea de recursos de propia jurisdicción o bien de recursos provenientes de jurisdicciones ajenas) y la falta de capacitación de recursos humanos, formados de acuerdo a las nuevas exigencias y desafíos del gobierno local. En este sentido, la falta de recursos no solo afecta la gestión e implementación de las nuevas políticas a cargo, sino también la posibilidad de llevar a cabo los cambios organizacionales necesarios para "potenciar la eficacia, eficiencia y efectividad de sus administraciones" (Tecco 1997). No basta con que los municipios cuenten con los recursos necesarios para implementar las políticas públicas que ahora tienen a su cargo, sino que resulta necesario también que cuenten con una estructura y una organización adecuada para llevar adelante tales políticas de la manera más efectiva y eficiente posible.

De esta manera, el escenario actual se presenta poco alentador para que los gobiernos locales puedan ejercer un efectivo grado de discreción (Pratchett 2004) y ven reducido en gran medida los ámbitos donde éstos puedan ejercer sus poderes de iniciativa y de inmunidad (Clark 1984), elementos éstos que, desde una perspectiva más funcionalista, hacen al concepto de autonomía local.

De ahí también la existencia de una cierta disonancia entre las preferencias de los actores gubernamentales del nivel local y los gastos efectivamente erogados por ellos. Esto puede ser explicado por el hecho de que los municipios han perdido (si es que alguna vez tuvieron) poder de fijar sus propias agendas; en cambio, sí es posible observar una clara penetración de los gobiernos intermedios (las provincias) a través 
de la orientación y fijación de las prioridades del gasto público municipal, de acuerdo a los intereses y prioridades no ya locales, sino del estado provincial o nacional. Queda de resalto así una clara predominancia de la perspectiva administrativista desde la cual son encaradas las relaciones intergubernamentales que contrasta con la visión autonómica plasmada en los textos constitucionales. Se produce en consecuencia una desvinculación entre el concepto de autonomía y las capacidades reales de los gobiernos locales, cuestión que se relaciona más íntimamente con el tamaño de los municipios, su perfil productivo, su capacidad recaudatoria, entre otros elementos claves que quedan fuera del análisis de la perspectiva jurídica-institucional.

Tanto las estas perspectivas teóricas normativistas/constitucionalistas como los propios textos constitucionales (que, en muchos casos, se nutrieron directamente de aquellas corrientes teóricas), se encuentran en gran medida disociadas de las realidades concretas que enfrentan los gobiernos locales, realidades que resultan ser muy dispares entre los propios municipios (dadas las grandes asimetrías que se observan) y según la provincia a la que pertenezcan; el legislador argentino se ha concentrado más en regular un régimen municipal genérico y abstracto y menos en propiciar instancias de colaboración mutua entre niveles de gobierno que permitieran construir agendas en función de las necesidades concretas de cada ente local, de acuerdo al contexto local, provincial y nacional.

Aun cuando algunas constituciones provinciales prevén instancias de participación, asociación y colaboración mutua, son pocas las experiencias concretas en las que se hayan materializado estas instancias y por lo general se observan proyectos o propuestas muy concretas orientadas a objetivos específicos y que pueden ser resumidos en dos: (a) la reducción del gasto local y logro de disciplina fiscal; y (b) orientar el gasto local a fines específicos. Ello implica afirmar que, aún en los casos donde se ha logrado cierto grado de coordinación entre niveles de gobierno, quienes han fijado la agenda han sido los niveles de gobierno superiores (las provincias respecto de sus municipios y el gobierno federal respecto de las provincias). En aquellas provincias donde se avanzó en materia de coordinación y negociación intergubernamentales verticales (provincia-municipios), las discusiones se centraron, en última instancia, en cuestiones relacionadas a la descentralización de recursos y formas de financiamiento del gasto local, más que en cuestiones relativas a una división del trabajo más adecuada y eficiente, y fueron llevados a cabo con una tendencia "top-down" y "de afuera hacia adentro" (Cáceres 2008, Parmigiani de Barbará 2006), es decir, donde los municipios tuvieron pocas oportunidades concretas de definir sus propias agendas.

\section{b. Discusión con la literatura actual y la necesidad de integrar perspectivas teóricas sobre el gobierno local}

Es posible afirmar que existe actualmente una clara desvinculación entre las perspectivas normativistas/constitucionalistas que priman en gran parte de la literatura local, las que concentran más sus miradas en un concepto de autonomía abstracto y desvinculado por tanto de las consecuencias prácticas que tales conceptos pueden acarrear, y dejan de lado importantes aportes que otros enfoques han realizado en la temática, tales como las relaciones intergubernamentales y las teorías 
del desarrollo local, que hacen mayor hincapié en las asimetrías reales entre los gobiernos locales y entre éstos y las instancias gubernamentales superiores.

Esta parte de la literatura local proviene del constitucionalismo y centra su análisis a partir de marcos jurídico-dogmáticos que en gran parte están desvinculados de las particularidades fácticas (económicas, geográficas, demográficas, etc.) de los gobiernos locales; en general, concluyen de manera coincidente en la capacidad constitucional de los gobiernos locales de recaudar recursos propios y en particular, aquellos de naturaleza tributaria, a partir del análisis de los aspectos formales/institucionales del municipio (Hernández 2003, Heredia 2005, Zarza Mensaque y Zarza Menzaque y Barrera Buteler 2010, entre otros). Otra parte importante de la literatura local y regional se focaliza, en términos generales, en cuestiones más vinculadas propiamente al análisis teórico del gobierno y el desarrollo local y en algunos casos centra su análisis en casos de estudios puntuales (Arocena 1997, 2013, (Cravacuore 2005, Cravacuore, llar y Villar 2004, Páez 2009, Villar 2004). Estos estudios tratan solo superficialmente los aspectos institucionales/formales del gobierno local en Argentina, aspectos que hacen a la capacidad institucional de los municipios de acuerdo a la estructura constitucional (nacional y provincial) que dan sustento jurídico a la realidad municipal en el país.

El reconocimiento de estas diferencias y asimetrías se constituye en un prerrequisito para la construcción de un concepto de autonomía lo suficientemente amplio para abarcar la realidad municipal y, al mismo tiempo, permitir un tratamiento diferenciado según el contexto y las características propias de cada gobierno municipal: "Esta situación plantea la necesidad de analizar las políticas de desarrollo local de manera diferenciada para cada tipo de municipio" (Villar 2004:5). En este punto la literatura actual no ha avanzado y tampoco se ha entablado un diálogo constructivo entre las distintas corrientes teóricas que encaran la cuestión de la autonomía desde perspectivas muy distintas. De ahí que este trabajo plantee la necesidad de un marco conceptual interdisciplinario y que abarque las distintas dimensiones que implica la autonomía local y de construir un concepto de autonomía que vincule los aspectos formales (institucionales/jurídicos) con aspectos de eficiencia y eficacia. Sharpe (1970) identifica tres principios que caracterizan al gobierno local: la libertad, la participación y la eficiencia. Estos tres principios no solo deben estar presentes, sino que además deben conjugarse de manera tal que "algún tipo de balance [pueda] ser alcanzado entre la capacidad funcional y las exigencias de la democracia", porque "un concejo municipal puede ser impecablemente democrático, pero puede ser incapaz de hacer algo de cierta importancia" (1970:160). Es a partir de estas diferenciaciones que se plantea la necesidad de construir marcos teóricos que coadyuven a entender las complejidades que presentan los distintos niveles municipales en Argentina y que puedan asimismo aportar elementos relevantes para la construcción de instituciones que se adecuen o contemplen la heterogeneidad de los gobiernos locales argentinos, caracterizados por grandes asimetrías.

A modo de conclusión preliminar y en base a la información estadística analizada, este trabajo busca dejar de resalto que el rol de los municipios en la gestación de la agenda pública local resulta fuertemente limitado por el factor económico financiero: "los 
recursos económicos municipales se destacan por su escasez. Ésta se debe a una pobre capacidad recaudadora y a sistemas de coparticipación que concentran el gasto en los niveles provincial y nacional. De esta forma se produce una dependencia económica que conduce a una de tipo político, generando una relación radial donde las provincias ocupan el centro sobre el que giran y se relacionan los municipios" (Villar 2004).

Esta dependencia (primero económica y luego política) condiciona fuertemente la decisión del gasto municipal, limitando la capacidad de decisión y de fijar agenda a sus principales actores políticos y, como tales, responsables de la gestión municipal ante la ciudadanía, lo que a su vez genera una falta de respuesta a las exigencias planteadas por la sociedad civil local, para la cual el principal centro de referencia para la solución de sus problemas son precisamente las autoridades municipales.

Ello evidencia la necesidad de una más clara vinculación (teórica y práctica) entre el concepto de autonomía y las reales posibilidades de los municipios en la decisión y gestión de políticas públicas, que incluya, entre otros aspectos, mecanismos de coordinación y negociación (formalizados e institucionalizados) entre los niveles de gobierno implicados en alguna o todas las fases de la política sobre la cual los gobiernos locales tienen reconocido algún grado de jurisdicción y un diseño institucional donde prime una clara y adecuada división del trabajo entre las distintas unidades gubernamentales.

De ello se desprende la necesidad de un marco teórico integrativo de ambas corrientes teóricas que permitan construir herramientas teóricas y metodológicas adecuadas para el análisis de los gobiernos locales en su conjunto pero considerando, al mismo tiempo, la enorme heterogeneidad, disparidad y asimetrías en las realidades de los municipios argentinos, entre los propios municipios y entre regiones. Un análisis teórico que integre ambas vertientes teóricas podría contribuir a una legislación más acorde con las distintas realidades provinciales y municipales, como así también a propiciar nuevas líneas de investigación que apunten a analizar la realidad municipal a partir de una perspectiva formal/constitucional y de los aportes teóricos de las relaciones intergubernamentales y el desarrollo local.

\section{BIBLIOGRAFÍA}

Abalos, María Gabriela (2003) “El Régimen Municipal en el Derecho Público Provincial Argentino: Principales Aspectos" en Pérez Guilhou, Dardo, dir, Derecho Público Provincial y Municipal, Buenos Aires: La Ley, pp. 317-346.

Álvarez Echagüe, Juan Manuel (2000) "Los municipios, su status jurídico y sus potestades financieras y tributarias en el marco de la Constitución reformada", Revista Impuestos, Tomo LVII-B.

Altavilla, Cristian (2015) "Asignación de competencias y atribución de facultades tributarias en el régimen municipal argentino. Alcances y límites del poder tributario municipal", en Hernández, Antonio M., Ernesto Rezk y Marcelo Capello, coords. Propuestas para fortalecer el federalismo argentino, Córdoba: Academia Nacional de Derecho y Ciencias Sociales de Córdoba, Instituto de Federalismo, pp. 413- 448. 
Altavilla, Cristian (2016a) Conflicto y Coordinación política en las Relaciones Intergubernamentales en Argentina. Un análisis neoinstitucional a través del Régimen de Coparticipación Federal de Impuestos, Tesis Doctoral, Universidad Nacional de Córdoba.

Altavilla, Cristian (2016b) "Fiscal (De)Centralization and Multilevel Governments in Different Institutional Settings. Argentina and Denmark in comparative perspective (2000-2015)" ponencia presentada en el 2016 Public Management Research Conference (PMRC), organizado por la Public Management Research Association (PMRA) y la Universidad de Aarhus, Aarhus, Dinamarca, 22-24 de junio.

Altavilla, Cristian (2017a) "Financiación de servicios públicos y relaciones intergubernamentales: valoración de la descentralización fiscal" ponencia presentada en el Workshop Internacional: "Servicios Públicos y ciudadanía en gobiernos multinivel; análisis comparado de su financiación", organizado por la Facultad de Derecho de la Universidad de Granada, España, 27 de junio.

Altavilla, Cristian (2017b) "El poder tributario en el régimen municipal de la Provincia de San Luis", en Anuario Revista Jurídica Región Cuyo - Argentina N ${ }^{\circ} 3$, Publicación del Instituto de la Región Cuyo de la Academia Nacional de Derecho y Ciencias Sociales de Córdoba, Buenos Aires: IJ Editores.

Argañaraz, Nadín, Sofía Celdrán y Mariano D’Angelo (2012) “Una 'constelación' de tasas municipales en la Argentina. Existen más de 130 tipos de tasas diferentes", Informe Económico, N. ${ }^{\circ} 153$, Instituto Argentino de Análisis Fiscal (IARAF) Córdoba, Argentina.

Arocena, José (1997) "Globalización, integración y desarrollo local. Apuntes para la elaboración de un marco conceptual" Revista Persona y Sociedad, ILADES, Santiago, Chile.

Arocena, José (2013) “El desarrollo local, una aproximación conceptual” en Revista Promoción del Desarrollo Local y Regional, №3, Ene-Nov., pp. 6-13.

Auyero, Javier (1996) "La doble vida del clientelismo político" en Sociedad, Revista de la Facultad de Ciencias Sociales (UBA).

Blom-Hansen, Jens (1999) "Policy-Making in Central-Local Government Relations: Balancing Local Autonomy, Macroeconomic Control, and Sectoral Policy Goals", Journal of Public Policy, Vol. 19, Issue 03, Sep., pp 237-264.

Cáceres, Pamela (2008) “¿Cómo se definen las agendas locales? A propósito del concepto de autonomía local", ponencia presentada en el XIII Congreso Internacional del CLAD sobre la Reforma del Estado y la Administración Pública, 4-8 de Noviembre, Ciudad Autónoma de Buenos Aires.

Cao, Horario, Coord., (2007) Introducción a la Administración Pública Argentina. Nación, provincias y municipios. Buenos Aires: Editorial Biblos.

Cetrángolo, Oscar y Juan P. Jiménez (2004) "Las Relaciones entre Niveles de Gobierno en Argentina. Raíces históricas, instituciones y conflictos persistentes", en Serie Gestión Pública, № 47, Octubre. Santiago de Chile: ILPES-ONU. 
Clark, Gordon (1984) "A Theory of Local Autonomy" Annals of the Association of American Geographers, 74 (2), pp. 195-208.

Cravacuore, Daniel (2005) "La articulación de actores para el desarrollo local" ponencia presentada en el VII Congreso Nacional de Ciencia Política de la SAAP, Universidad Católica de Córdoba - Universidad Nacional de Córdoba, Córdoba, Argentina.

Cravacuore, Daniel, Sergio Ilari y Alejandro Villar (2004) La Articulación en la Gestión Municipal: Actores y Políticas, Quilmes: Universidad Nacional de Quilmes.

F.A.U.I. (Fiscal Austerity and Urban Innovation) Encuesta del Proyecto Internacional Fiscal Austerity and Urban Innovation, Universidad de Chicago, (2004-2006) realizada en Argentina por el proyecto "Régimen Político y Cultura Política" de la Universidad Nacional de San Luis, sobre Municipios de más de 10.000 habitantes.

Flores, Héctor; Iparraguirre, Estela (2010) "El municipio: actores en el proceso de decisiones gubernamentales", ponencia presentada en las IV Jornadas Nacionales de investigadores de las economías regionales, Universidad Nacional de Entre Ríos, Facultad de Ciencias Económicas, Paraná, Provincia de Entre Ríos, Paraná 11 y 12 de noviembre

Giuliani Fonrouge, Carlos (2003) Derecho Financiero, Tomo I, Buenos Aires: La Ley.

Heredia, José Raúl (2005) El poder tributario de los municipios, Santa Fe: RubinzalCulzoni.

Hernández, Antonio M., (2003) Derecho municipal. Parte general, México: Universidad Nacional Autónoma de México, Instituto de Investigaciones Jurídicas, Serie Doctrina Jurídica, № 159.

Iparraguirre Estela; Flores, Héctor y Gil, Martín (2012) Los actores sociales y políticos y las decisiones de gasto a nivel municipal. Un abordaje desde la autonomía municipal. X Congreso Nacional y III Congreso Internacional sobre Democracia. Universidad Nacional de Rosario.

Jones, Mark, Pablo Sanguinetti y Mariano Tommasi (1997) "Politics, Institutions, and Public Sector Spending in the Argentine Provinces", Documento de Trabajo $\mathrm{N}^{\circ}$ 17, Universidad de San Andrés, Agosto.

López Accotto, Alejandro, Carlos R. Martínez, Martín Mangas y Ricardo Paparas (2016) Finanzas públicas y política fiscal. Conceptos e interpretaciones desde una visión Argentina. Los Polvorines: Ediciones UNGS (Universidad Nacional de General Sarmiento).

Macon, Jorge (1985) Finanzas Públicas Argentinas. Editorial Macchi, Buenos Aires.

Navarro Yánez, Clemente, Ramírez, M. Antonia (2005): Una propuesta para el análisis de la acción de los gobiernos locales. Universidad Pablo de Olavide. Sevilla.

Oates, Wallace (1972) Fiscal Federalism, New York: Harcourt Brace Jovanovich.

Páez, Mónica. (2009) "Gobiernos locales y desarrollo: un estudio de caso para Argentina", en Revista Trabajo y Sociedad, № 12, Vol. 11. 
Parmigiani de Barbará, Myriam Consuelo (2006) "Modelos de regionalización subnacional en la Provincia de Córdoba", en Anuario del Centro de Investigaciones Jurídicas y Sociales, Facultad de Derecho y Ciencias Sociales, Universidad Nacional de Córdoba, La Ley, pp. 157-170.

Porto, Alberto, Marcelo Garriga y Walter Rosales (2010) "Tamaño del grupo y variables fiscales municipales", ponencia presentada en las 43 Jornadas Internacionales de Finanzas Públicas, Universidad Nacional de Córdoba, Córdoba, Argentina.

Pratchett, Lawrence (2004) "Local Autonomy. Local Democracy and the New Localism" Political Studies, Vol.52, 358-375, Malden, USA.

Rodden, Jonathan (2009) "Federalism and Inter-Regional Redistribution", en Bosch, Núria, Marta Espasa y Albert Solé-Ollé, The Political Economy of Inter-regional Fiscal Flows, Edward Elgar, pp. 191-219.

Rosatti, Horacio (2012a) Tratado de Derecho Municipal. Tomo I, Santa Fe: RubinzalCulzoni.

Rosatti, Horacio (2012a) Tratado de Derecho Municipal. Tomo I, Santa Fe: RubinzalCulzoni.

Sharpe, L. James (1970) "Theories and Values of Local Government", Political Studies, Vol. XVIII, No. 2, pp. 153-174.

Tiebout, Charles M. (1956), "A Pure Theory of Local Expenditures", The Journal of Political Economy, Vol. 64, No. 5, (Oct., 1956), pp. 416-424.

Villar, Alejandro (2004) "Una década de desarrollo local en Argentina. Balance y perspectivas", Revista Mundo Urbano N²4 Universidad Nacional de Quilmes, publicación online, disponible en: http://www.mundourbano.unq.edu.ar/index.php/ano-2004/48-numero24/172-una-decada-de-desarrollo-local-en-argentina-balance-y-perspectivas.

Weber, Max (1974) Economía y Sociedad, México: Fondo de Cultura Económica.

Zarza Menzaque, Alberto y Guillermo Barrera Buteler (2010), dirs., Introducción al Derecho Municipal, Córdoba: Advocatus. 
TABLA 13: RECURSOS MUNICIPALES POR TIPO. AÑO 2003

\begin{tabular}{|l|r|}
\hline \multicolumn{1}{|c|}{ RECURSOS } & MILLONES DE PESOS \\
\hline Impuestos Municipales & 2.269 \\
\hline Regalias & 1.333 \\
\hline Tasas, derechos y contribuciones & 35.009 \\
\hline Otros recursos propios & 5.048 \\
\hline Subtotal recursos propios & $\mathbf{4 3 . 6 5 9}$ \\
\hline Coparticipación y otras transferencias automáticas similares & 47.283 \\
\hline Fondo Federal Solidario & 2.824 \\
\hline Transferencias provinciales y nacionales no automáticas & 14.249 \\
\hline Subtotal recursos no propios & $\mathbf{6 4 . 3 5 6}$ \\
\hline TOTAL & $\mathbf{1 0 8 . 0 1 5}$ \\
\hline
\end{tabular}

Fuente: López Accotto et al. 2016.

TABLA 14: IMPUESTOS MUNICIPALES POR PROVINCIA

\begin{tabular}{|l|l|}
\hline \multicolumn{1}{|c|}{ PROVINCIA } & \multicolumn{1}{c|}{ IMPUESTOS } \\
\hline CHUBUT & Automotores, inmobiliario (urbano y rural), ingresos brutos. ${ }^{*}$ \\
\hline CHACO & Automotores, inmobiliario urbano, inmobiliario rural. \\
\hline CORRIENTES & Automotores, inmobiliario urbano. \\
\hline FORMOSA & Automotores, inmobiliario urbano. \\
\hline SALTA & Automotores, inmobiliario urbano. \\
\hline SANTA CRUZ & Automotores, inmobiliario urbano. \\
\hline TIERRA DEL FUEGO & Automotores, inmobiliario urbano. \\
\hline CORDOBA & Automotores. \\
\hline JUJUY & Automotores. \\
\hline NEUQUÉN & Automotores. \\
\hline
\end{tabular}

* No incluye el tramo de ingresos brutos que se percibe mediante convenio multilateral.

Fuente: López Accotto et al. 2016.

TABLA 15: PRESIÓN FISCAL POR NIVEL DE GOBIERNO, EN PORCENTAJE DEL PBI. PERÍODO 1993-2013

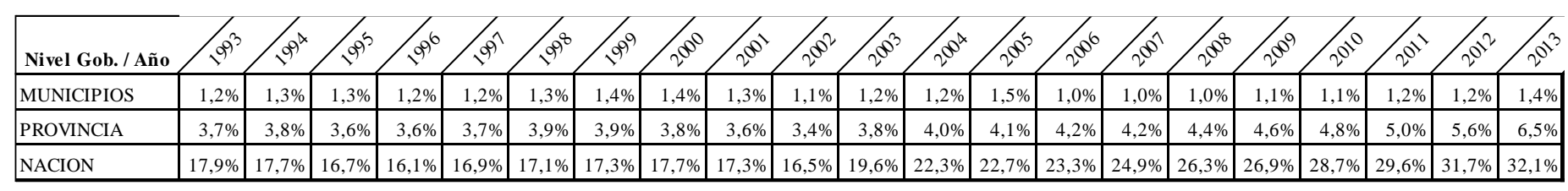

Fuente: Elaboración propia en base a información proporcionada por López

Accotto et al. 2016. 